\title{
How much money can be saved by applying intravenous antibiotics once instead of several times a day?
}

\author{
D. Mertz $\cdot$ H. Plagge $\cdot$ S. Bassetti $\cdot$ M. Battegay $\cdot$ \\ A. F. Widmer
}

Received: 20 April 2010/Accepted: 5 October 2010/Published online: 28 October 2010

(C) Urban \& Vogel 2010

\begin{abstract}
Background The preparation, administration and monitoring of intravenous (IV) applications are time consuming and require human resources. We estimated the potential time and cost savings by replacing antibiotics given 3-4 times daily with antibiotics with similar spectrum and efficacy given once daily.

Methods The savings of indirect costs were estimated based on the antibiotic consumption data of a two-year period (i.e. 2007 and 2008), a nurse's mean workload per application and the average nurse's salary in Switzerland. Results The consumption of IV antibiotics in 2007 and 2008 at the University Hospital of Basel was 29.0 and 32.2 defined daily doses (DDD) per 100 patient days, respectively. Nurses spent an estimated $13,786 \mathrm{~h}$ on the application of the estimated 82,715 does of IV antibiotics. A total of 56,404 applications or nursing staff time costs of 338,436 Swiss Francs (CHF; 236,669 €), equal to $16 \%$ of the overall costs spent on purchasing antibiotics in the year 2008, may have been saved by switching multiple-dose
\end{abstract}

D. Mertz · S. Bassetti · M. Battegay · A. F. Widmer $(\square)$ Division of Infectious Diseases and Hospital Epidemiology, University Hospital Basel, Petersgraben 4, 4031 Basel, Switzerland

e-mail: widmera@uhbs.ch

H. Plagge

Hospital Pharmacy, University Hospital Basel, Basel, Switzerland

S. Bassetti

Department of Internal Medicine, Kantonsspital Olten,

Olten, Switzerland antibiotics to a hypothetical once-daily antibiotic. Including disposable materials, $21 \%$ or $456,884 \mathrm{CHF}(319,499 €)$ could be saved annually (purchase costs not taken into account).

Conclusion We found a potential cost saving of $21 \%$ of the purchase costs in a 750-bed institution. Hence, indirect costs should be included in the calculation of the total cost for the application of broad-spectrum IV antibiotics. Switching from a 3-4 times daily application to a oncedaily antibiotic should be considered if a once-daily antibiotic is deemed equally effective and has a similar spectrum.

Keywords Antibiotics - Cost saving - Once daily · Administration · Indirect costs

\section{Introduction}

The preparation, administration and monitoring of intravenous (IV) applications is time and cost consuming. In pharmacoeconomic evaluations, it is important to include the nursing staff time and the indirect costs associated with the application of IV antibiotics to the direct costs for the purchase of these antibiotics [1-3]. Detailed data on how much nursing staff time and expenses may be saved by the reduction of the number of IV applications of antibiotics in a hospital is scarce and is limited to particular patient groups $[4,5]$.

This analysis aims to calculate the amount of time and the associated costs which can be saved from the perspective of a hospital by the use of an equally effective hypothetic antibiotic which is applied once daily, replacing the beta-lactam antibiotics which commonly require several administrations per day. 


\section{Methods}

The University Hospital of Basel is a 750-bed tertiary care centre serving about 27,000 admissions annually. The consumption data of antibiotics in defined daily doses (DDD) of the following IV antibiotics of interest were used for this study (the typical number of applications per day at our institution within parentheses): amoxicillin (4), amoxicillin/clavulanate (3), penicillin (4), flucloxacillin (4), piperacillin/tazobactam (3), cefepime (3), imipenem/cilastatin (4) and meropenem (3). Because the definition of the DDD does not necessarily represent the daily dose typically administered in our hospital, the number of grammes per year was calculated as the basis for this analysis. The data was extracted from the hospital pharmacy.

\section{Analysis}

On average, one application of an IV antibiotic takes $10 \mathrm{~min}$, based on the validated computerised nursing software that continuously measures nurses' workload, called 'Leistungserfassung in der Pflege' (LEP; http:// www.lep.ch/index.php/en/). LEP is the standard software in most Swiss hospitals used to allocate nursing staff time. Every single task conducted by nurses is registered by each individual nurse either during breaks from clinical work or at the end of the shift. According to the LEP system, an application of IV antibiotics is a 'simple' intravenous application and represents $10 \mathrm{~min}$ of work. The alternative categories in LEP, 'very simple', 'complex' and 'very complex' intravenous application (5, 20 and $30 \mathrm{~min}$, respectively), are only rarely used in the context of the administration of IV antibiotics. Because the workload cannot be registered in 1-min steps, a published average duration of $6.77 \mathrm{~min}$ [4] for the duration of one IV application instead of $10 \mathrm{~min}$ was assumed for sensitivity analysis.

Based on the assumption that the total number of applications per antibiotic would be replaced by a oncedaily IV application, the reduction in workload and costs for IV applications per year were calculated. The costs are reported in the local currency (Swiss Francs, CHF) and in Euros $(€)$, calculated at an exchange rate of 1.43 .

\section{Results}

The overall consumption of antibiotics in 2007 and 2008 was 50.4 and 54.0 DDD per 100 patient days and the costs were 2,441,465 CHF $(1,707,318 €)$ and 2,155,607 CHF $(1,507,417 €)$, respectively. The consumption of IV antibiotics was 29.0 and 32.2 DDD per 100 patient days or 208,180 and $194,747 \mathrm{~g}$ of antibiotics per year, respectively (Table 1). Therefore, about 59\% of antibiotics were administered intravenously.

A total of 56,404 applications may have been saved by the use of a hypothetic once-daily antibiotic. As every application takes, on average, $10 \mathrm{~min}$ and the usual hourly wage of a nurse in Switzerland is $36 \mathrm{CHF}$ (25€), without taking the purchase costs into account, a potential cost saving of $338,436 \mathrm{CHF}(236,669 €)$ per year was calculated. This cost saving equals $16 \%$ of the overall costs

Table 1 Consumption data of antibiotics of interest, potential reduction of applications per year, and time and cost savings

\begin{tabular}{|c|c|c|c|c|c|c|c|}
\hline Antibiotic regimen & $\begin{array}{l}\text { Typical } \\
\text { no. of daily } \\
\text { applications }\end{array}$ & $\begin{array}{l}\text { Grammes } \\
\text { per } \\
\text { application }\end{array}$ & $\begin{array}{l}\text { Purchase } \\
\text { costs } \\
\text { per day }\end{array}$ & $\begin{array}{l}\text { Grammes } \\
\text { used in } 2007\end{array}$ & $\begin{array}{l}\text { Grammes } \\
\text { used in } 2008\end{array}$ & $\begin{array}{l}\text { Mean no. of } \\
\text { applications } \\
\text { per year }\end{array}$ & $\begin{array}{l}\text { Reduction in } \\
\text { the no. of } \\
\text { applications }\end{array}$ \\
\hline Amoxicillin & 4 & 2.0 & $58 \mathrm{CHF}$ & 3,403 & 3,330 & 1,683 & 1,262 \\
\hline Amoxicillin/clavulanate $1.2 \mathrm{~g}$ & 3 & 1.2 & $9 \mathrm{CHF}$ & 22,205 & 20,570 & 17,823 & 11,882 \\
\hline Amoxicillin/clavulanate $2.2 \mathrm{~g}$ & 3 & 2.2 & $14 \mathrm{CHF}$ & 30,706 & 34,472 & 14,813 & 9,875 \\
\hline Cefepime & 3 & 2.0 & $74 \mathrm{CHF}$ & 2,194 & 8,625 & 2,705 & 1,803 \\
\hline Flucloxacillin & 4 & 2.0 & $88 \mathrm{CHF}$ & 10,725 & 11,300 & 5,506 & 4,130 \\
\hline Imipenem/cilastatin & 4 & 0.5 & $132 \mathrm{CHF}$ & 1,013 & 1,405 & 2,418 & 1,813 \\
\hline Meropenem & 3 & 1.0 & $173 \mathrm{CHF}$ & 9,980 & 10,125 & 10,053 & 6,702 \\
\hline Penicillin & 4 & 3.0 & $15 \mathrm{CHF}$ & 14,918 & 18,205 & 5,521 & 4,140 \\
\hline Piperacillin/tazobactam & 3 & 4.5 & $78 \mathrm{CHF}$ & 99,604 & 100,148 & 22,195 & 14,796 \\
\hline \multicolumn{7}{|l|}{ Overall reduction of applications } & 56,404 \\
\hline \multicolumn{7}{|l|}{ Time savings in hours } & 9,401 \\
\hline \multicolumn{7}{|l|}{ Hourly wage of a nurse } & $36 \mathrm{CHF}$ \\
\hline \multicolumn{7}{|l|}{ Potential cost savings of wages } & $338,436 \mathrm{CHF}$ \\
\hline
\end{tabular}

Purchase costs are based upon ex-factory prices in 2008 for the typical daily dose applied in our institution, i.e. the typical number of daily applications multiplied by grammes per application; CHF Swiss Francs 
spent on purchasing antibiotics in the year 2008, i.e. the direct costs.

The disposable materials, including $100 \mathrm{ml}$ of sodium chloride, would add another $2.10 \mathrm{CHF}$ (1.47€) per application or $118,448 \mathrm{CHF}(82,831 €)$ for the 56,404 applications potentially saved. In total, $456,884 \mathrm{CHF}(319,499 €)$ or $21 \%$ of the purchase costs could be saved without taking the purchase costs into account.

Importantly, not only the cost savings due to a lower number of administrations but also the potentially higher purchase costs of the hypothetical antibiotic must be taken into account. For example, the reduction of the number of applications from three doses to one results in potential cost savings of $12 \mathrm{CHF}$ (8.40€) per day and patient. Assuming that, previously, piperacillin/tazobactam $4.5 \mathrm{~g}$ (purchase costs of $78 \mathrm{CHF} / 55 €$ per day) was administered thrice daily and replaced by the hypothetical antibiotic, the once-daily administration of the latter would be less expensive as long as its purchase cost would not exceed 90 $\mathrm{CHF}$ (63€) per day. For comparison, the purchase costs for ertapenem is $71 \mathrm{CHF}(50 €)$ per day. In contrast, a oncedaily drug replacing amoxicillin/clavulanate (purchase costs of $9 \mathrm{CHF} / 6.30 €$ per day) would need to cost less than $21 \mathrm{CHF}(14.70 €)$ and, therefore, replacing amoxicillin/ clavulanate by either ertapenem or ceftriaxone (33 CHF/ $23.10 €)$ does not result in an overall cost benefit.

\section{Discussion}

Our study shows in a tertiary-care hospital, that $21 \%$ of the direct costs or $319,499 €$ per year could be saved by reducing nursing staff time and the costs for disposable materials if multiple-dose antibiotics are replaced by single-dose antibiotics.

No such antibiotic to be applied once daily potentially replacing beta-lactams in all indications exists nowadays. There are some antibiotics (e.g. ceftriaxone and ertapenem) approved for once-daily application which may replace other beta-lactams used in this study in a majority of indications. However, these antibiotics are approved only for some specific infections and have different antimicrobial spectra. Therefore, the cost-saving potential would be significantly smaller than what we have estimated in this study. Furthermore, in order to reduce the spread of resistance, antibiotics with a narrow spectrum should be preferred and broad-spectrum antibiotics such as ertapenem should only be used if narrower antibiotics are not more appropriate. Furthermore, due to the longer half-life of antibiotics applied once daily, the duration of suboptimal concentrations of the antibiotic may be prolonged. Therefore, from a theoretical point of view, the longer halflife might be a disadvantage in regards to the selection and development of resistance. However, such an emergence of resistance was not frequently observed with once-daily IV antibiotics. Continuous perfusion does not have this theoretical potential and could also reduce the workload for nurses.

The reduction of the workload for health care workers could either result in cost savings if the number of health care workers would be reduced or, alternatively, the cost saving can be referred to as opportunity costs and the time saving could be used for other tasks, with the aim to improve the quality of care. Once instead of three or four times daily administration has potential benefits in addition to save nursing staff time, such as, most importantly, earlier discharge, which may further significantly reduce the costs for the health care system $[6,7]$ and a reduction of errors and omitted doses. In fact, recent studies found that $22-31 \%$ of doses were inappropriately prepared and 19-49\% of doses were inappropriately administered [8, 9]. It is conceivable that these mistakes may be reduced by the use of a once-daily regimen [7]. Furthermore, fewer manipulations on the IV line may reduce the incidence of secondary infections [10]. Importantly, early switching from IV to the oral application of antibiotics is an even better way to reduce the number of IV administrations [3] and should not be neglected due to the potential ease and cost savings of once-daily IV administrations.

Our results are based on a projection using assumptions. This limits the interpretation and generalisability of our results beyond our institution. We assumed that all antibiotics were given at the standard dose in terms of grammes per application and the numbers of daily applications. The duration of the preparation and administration of IV drugs can vary from drug to drug [1]. The $10 \mathrm{~min}$ of nursing staff time required for applications of an antibiotic assumed in this study is high in comparison to other studies measuring the time for preparation and application [1, 4]. The assumption that the application of IV antibiotics takes $6.77 \mathrm{~min}$ as suggested in the analysis by Tice et al. [4] would lower the potential of cost savings to $67.7 \%$ of the findings of our primary analysis. However, in our hospital, the preparation of antibiotics is done by nurses and not by pharmacy technicians as, e.g. in the US, and the nursing time of $10 \mathrm{~min}$ includes monitoring of the patient after having started the infusion and stopping and removal of the infusion at the end as well. Our study represents the nursing time and costs in a Swiss hospital and both variables may vary in other hospitals and other countries. However, the importance of indirect costs and the potential to save nursing time and costs by using a once-daily antibiotic almost certainly applies all over the world. The wagesalthough very conservatively estimated in this study-may be significantly higher than in other countries. On the other hand, our institution has a low consumption of antibiotics, 
therefore, potentially underestimating the additional expenses for multiple doses in other institutions. The additional costs for pharmacy technicians, depreciation of medical equipment (e.g. infusion pumps), unallocated time and overheads were not included in this cost analysis. These additional costs are very difficult to evaluate and are low compared to the costs of the nursing time calculated in this study.

In conclusion, the dosing regimen strongly influences the total cost for IV therapy: indirect costs for application of the antibiotic should be included in the calculation of the total cost for IV antibiotics. Switching from a 3-4 times daily application to a once-daily antibiotic should be considered if a once-daily antibiotic with similar spectrum and efficacy is available: the calculation of the situation at our institution resulted in a potential cost saving for nursing staff time of $16 \%$, and $21 \%$ when including disposable materials of the purchase costs in our institution.

Acknowledgments This work was supported by an unrestricted grant from Merck Sharp \& Dohme-Chibret (MSD) AG, Switzerland. The study sponsor did not participate in the study design, data analysis, collection, data interpretation or in the decision to submit this article for publication.

Conflict of interest None.

\section{References}

1. van Zanten AR, Engelfriet PM, van Dillen $K$, van Veen M, Nuijten MJ, Polderman KH. Importance of nondrug costs of intravenous antibiotic therapy. Crit Care. 2003;7:R184-90.
2. Flynn E, Marciniak A, Barbabietola G, Oppenheim BA, Roberts C, Barker K. A multi-centre comparison of nursing staff time required for the preparation and administration of liposomal amphotericin B and amphotericin B deoxycholate vs. voriconazole. J Clin Nurs. 2009;18:1168-79.

3. Mertz D, Koller M, Haller P, Lampert ML, Plagge H, Hug B, Koch G, Battegay M, Flückiger U, Bassetti S. Outcomes of early switching from intravenous to oral antibiotics on medical wards. J Antimicrob Chemother. 2009;64:188-99.

4. Tice AD, Turpin RS, Hoey CT, Lipsky BA, Wu J, Abramson MA. Comparative costs of ertapenem and piperacillin-tazobactam in the treatment of diabetic foot infections. Am J Health Syst Pharm. 2007;64:1080-6.

5. Clay PG, Graham MR, Lindsey CC, Lamp KC, Freeman C, Glaros A. Clinical efficacy, tolerability, and cost savings associated with the use of open-label metronidazole plus ceftriaxone once daily compared with ticarcillin/clavulanate every 6 hours as empiric treatment for diabetic lower-extremity infections in older males. Am J Geriatr Pharmacother. 2004;2:181-9.

6. Tice AD, Hoaglund PA, Nolet B, McKinnon PS, Mozaffari E. Cost perspectives for outpatient intravenous antimicrobial therapy. Pharmacotherapy. 2002;22:63S-70S.

7. Tice AD. Ertapenem: a new opportunity for outpatient parenteral antimicrobial therapy. J Antimicrob Chemother. 2004;53:ii83-6.

8. Wirtz V, Taxis K, Barber ND. An observational study of intravenous medication errors in the United Kingdom and in Germany. Pharm World Sci. 2003;25:104-11.

9. Barker KN, Flynn EA, Pepper GA, Bates DW, Mikeal RL. Medication errors observed in 36 health care facilities. Arch Intern Med. 2002;162:1897-903.

10. Mermel LA, Allon M, Bouza E, Craven DE, Flynn P, O’Grady NP, Raad II, Rijnders BJ, Sherertz RJ, Warren DK. Clinical practice guidelines for the diagnosis and management of intravascular catheter-related infection: 2009 Update by the Infectious Diseases Society of America. Clin Infect Dis. 2009;49:1-45. 